\title{
Representação política e interesses particulares na saúde: 0 caso do financiamento de campanhas eleitorais pelas empresas de planos de saúde privados no Brasil
}

Mário Scheffer ${ }^{1}$

Lígia Bahia ${ }^{2}$

\section{Introdução}

Diversas evidências são constantemente evocadas para demonstrar que as organizações e empresas de natureza privada, lucrativas ou filantrópicas, que atuam no setor saúde no Brasil, influenciam na definição das políticas e nas legislações setoriais. No entanto, são complexos os dispositivos acionados para proteger ou favorecer a atuação desses grupos que estabeleceram, ao longo do tempo, elos bastante estreitos com o Poder Executivo. O Estado, por meio de políticas econômicas, instrumentos jurídico-administrativos e outras intervenções, contempla interesses de estabelecimentos de saúde (hospitais, clínicas e unidades de apoio diagnóstico e terapêutico), de empresas que comercializam planos e seguros de saúde, e de empresas do complexo industrial da saúde, especialmente a indústria farmacêutica e de equipamentos.

Durante o regime militar, as relações entre os grupos econômicos e os ocupantes de cargos governamentais - os denominados "anéis burocráticos" uniram os setores industriais exportadores, contratadores de obras e extrativoexportadores. O grande capital multinacional e o capital financeiro se articularam aos funcionários do Estado (civis e militares) para garantir seus interesses e sustentar a nova etapa da acumulação e do crescimento econômico. Relações antes estabelecidas por meio de partidos políticos que possuíam alguma influência no Legislativo, transferiram-se para o interior dos ministérios e das autarquias a eles subordinadas, sob a tutela da Presidência da República (Cardoso, 1975).

No contexto de redemocratização do país, a plataforma essencialmente conservadora dos grupos empresariais privados foi confrontada com a agenda reformista apresentada pelo movimento sanitário, pelas entidades de profissionais de saúde, instituições de ensino e pesquisa, movimentos populares e associações da sociedade civil, que interferiram decisivamente no processo de debate, elaboração e aprovação da Constituição de 1988. Naquele momento, envolto na atmosfera carregada de tensões impostas pelo setor privado, o texto constitucional introduziu a concepção da relevância pública da saúde.

No entanto, a insígnia da complementaridade do privado, sob a qual se sentiram abrigados segmentos empresariais de distintas naturezas e competências, culminou por não especificar, no texto constitucional, o âmbito de sua

\footnotetext{
1 Departamento de Medicina Preventiva, Faculdade de Medicina, Universidade de São Paulo. Av. Dr. Arnaldo, 455, Cerqueira César. São Paulo, SP, Brasil. 01.246-903. mscheffer@uol.com.br ${ }^{2}$ Laboratório de Economia Política da Saúde da Universidade Federal do Rio
} 
abrangência. Assim, a heterogeneidade dos planos e seguros de saúde privados - que, no final dos anos 1980, já eram responsáveis por parte da cobertura da assistência médico-hospitalar de trabalhadores especializados, dos funcionários de empresas estatais e de uma parcela considerável de servidores públicos das três esferas de governo - podia ser atribuída à ausência de regulação e de normas explícitas para a atuação desse setor.

A inclusão do Sistema Único de Saúde (SUS) na Constituição Federal representou a vitória das teses aprovadas na VIII Conferência Nacional de Saúde de 1986. O SUS foi apoiado pela aliança entre os partidos com um perfil, então, progressista (PSDB, PT, PDT, PCB, PCdoB e parte do PMDB) no Congresso, aos quais se uniram o movimento sindical e alguns movimentos populares (como, por exemplo, o Plenário Pró-participação Popular na Constituinte). Essa coalizão conseguiu fazer frente aos setores mais conservadores do PMDB, PTB, PDS e PFL, que, organizados em torno do "Centrão", defendiam os interesses do setor privado da saúde.

Segundo depoimento do médico e ex-deputado federal Eduardo Jorge, dois fatores teriam contribuído para a vitória inicial do movimento sanitário na Constituinte: 1) o fato de esse movimento, ao contrário do setor privado, ter iniciado o processo constituinte com uma proposta já consolidada; e 2) a opção, por parte dos setores conservadores, em priorizar a discussão temática das questões relativas à ordem econômica, o que permitiu que um arco de alianças envolvendo o centro e a esquerda dominasse a composição das comissões e subcomissões da área social durante a tramitação no Legislativo (Pereira, 1996).

O deslocamento do centro das decisões sobre as políticas públicas, do Poder Executivo para o Parlamento, conferiu maior visibilidade aos interesses dos grupos privados da saúde. O projeto de elaboração da Reforma Sanitária brasileira também expôs a relação entre os estabelecimentos filantrópicos e privados e as políticas públicas de Previdência Social, não apenas em termos da remuneração dos serviços prestados, mas também em relação às acepções sobre o caráter de mercadoria dos procedimentos médico-hospitalares.

Ao longo da consolidação da democracia, esses mesmos grupos passaram a investir sistematicamente nos espaços de representação política para viabilizar suas demandas particulares. Ao mesmo tempo, permaneceram atentos a iniciativas de caráter normativo emanadas do Poder Executivo. Não por acaso, cavaram o front da disputa pela nomeação de seus representantes diretos em cargos da saúde considerados estratégicos à preservação e à ampliação de seus negócios.

Diante da necessidade de subsidiar o conhecimento sobre a repercussão das pressões desse segmento empresarial sobre o Parlamento, o presente trabalho dedica-se a sistematizar informações referentes a doações dos planos e seguros de saúde para campanhas eleitorais. Para tanto, se apoia na pesquisa dos dados oficiais processados pelo TSE, na consulta da legislação e na literatura sobre o financiamento das campanhas eleitorais e as perspectivas da reforma política

\section{O "caixa dois" nas eleições}

As relações entre o Parlamento e grupos organizados da sociedade civil não são facilmente evidenciáveis. São distintas as lógicas que movem os grupos econômicos setorizados, daquelas que determinam a atuação dos que defendem interesses mais coletivos e difusos. Já os planos estratégicos dos parlamentares visam, sobretudo, dar visibilidade à sua atuação, com o objetivo final da reeleição (Pilatt, 2006). Mas as preocupações em torno da necessidade de ampliar o controle social sobre o Parlamento têm proporcionado mudanças significativas na percepção, análise de informações e aprimoramento da legislação eleitoral.

O principal problema sempre foi a existência de dois caixas de campanha e de uma teia de relações entre os candidatos a mandatos políticos e os grupos de interesses particulares. A utilização de "recursos não contabilizados", mais conhecida como "caixa dois", é prática corrente no Brasil. A Lei Eleitoral (Lei no 12.034, de 29 de setembro de 2009), que entrou em vigor em 2010, trouxe avanços, mas não permite que a Justiça Eleitoral trace o caminho seguido pelos recursos desde o doador até o último destinatário. São frágeis, portanto, os mecanismos capazes de coibir o "caixa dois" e as doações ocultas. Existe, ainda, a possibilidade de os partidos assumirem o pagamento das despesas de candidatos. Como 
os partidos têm um leque mais aberto de financiadores, a utilização, mediada pelas legendas, de fontes de financiamento que estariam vedadas aos candidatos, impede a identificação dos reais destinatários.

\section{As doações eleitorais registradas}

O TSE divulga, em sua página na internet (www.tse.gov.br), dados sobre a prestação de contas das eleições desde 2002. Ainda que em caráter preliminar e exploratório, são possíveis levantamentos sobre o financiamento de campanhas e a relação entre doadores (empresas e pessoas físicas) e candidatos eleitos. Abre-se a perspectiva de se exercer um monitoramento mais sistemático sobre a atuação dos parlamentares, porém recomenda-se o exame cauteloso de inferências extraídas das informações sobre os doadores e receptores do financiamento de campanhas eleitorais. Permanece incalculável a persistência e o impacto do "caixa dois" e das inúmeras possibilidades indiretas de se contribuir para os comitês de campanha, como: a cobertura indireta de custos de produtos, serviços gráficos, campanhas publicitárias, imóveis para comitês, dinheiro vivo etc.

Além disso, é preciso sublinhar que não é facilmente detectável a relação causal entre o financiamento das campanhas e a atuação do parlamentar em defesa de determinados interesses políticos e econômicos. É razoável supor que a doação possa ter sido inspirada nos compromissos anteriores do parlamentar com o interesse em questão, como ocorre com os representantes das bancada temáticas do parlamento, a exemplo da bancada ruralista.

Ainda assim, o mapeamento inicial das relações entre as empresas de planos e seguros de saúde e os representantes políticos é útil para que as entidades da sociedade civil possam acompanhar com mais precisão a atuação dos parlamentares e ocupantes de cargos majoritários. O volume de financiamento tem relação direta com a chance de o candidato se eleger, e a contribuição de forma desigual para as campanhas pode contribuir para a deterioração da representação democrática. Por isso, é fundamental verificar os possíveis efeitos desse tipo de "incentivo" sobre a atuação parlamentar. Isso requer monitoramento constante e acompanhamento individualizado da produção parlamentar e dos ocupantes de cargos majoritários. O atendimento de interesses particulares em detrimento do bem público e do interesse coletivo é um conflito que pode surgir na prática cotidiana do parlamentar, na apresentação de projetos de lei e outras proposições, nas comissões parlamentares e nos posicionamentos públicos. Cabe às comissões permanentes e temáticas, comissões especiais e comissões parlamentares de inquérito (as duas últimas têm duração definida) a análise dos projetos que tramitam no Congresso, além de estudos e investigações sobre temas definidos.

Os parlamentares se veem diante de variados "cardápios" de composição de interesses e agentes sociais. Geralmente, ocupam espaço na agenda dos parlamentares: a defesa dos programas partidários, os interesses das bases eleitorais regionais e locais, a interlocução com o Poder Executivo, as demandas de movimentos específicos (gênero, patologias, deficiências físicas, discriminações étnicas, raciais, por orientação sexual etc.), mas também as reivindicações de grupos empresariais setorizados e a formulação da legislação sobre temas econômicos e sociais nacionais.

Embora a natureza mais paroquial ou nacional do Congresso, vis-à-vis suas atribuições e prerrogativas, assim como a composição e a representatividade de suas bancadas, seja objeto de pesquisas sistemáticas (Rodrigues, 2002; Santos, 1998), são tênues as evidências sobre as relações entre poder econômico e eleições. Daí a relevância de se problematizar a associação entre estrutura do financiamento de campanhas e os riscos e grau de dependência entre os doadores e seus beneficiários.

\section{Metodologia}

Desde as eleições de 2006 é possível uma aproximação mais realista da participação dos doadores em campanhas eleitorais, com informações mais consistentes do que as disponibilizadas nas eleições anteriores. O TSE mantém on line o Sistema de Divulgação dos Financiamentos de Campanha Eleitoral para as Eleições. Este instrumento possibilita a consulta pública sobre financiamento da campanha, no caso das eleições de 2006. 
Para identificar as empresas de planos de saúde privados na condição de doadoras, utilizou-se a relação de empresas operadoras de planos de saúde (razão social e CNPJ) em atividade, oficialmente inscritas e registradas na Agência Nacional de Saúde Suplementar (ANS) no ano analisado - informação disponível no site institucional www.ans.gov.br.

Foram pesquisados, individualmente, no site do TSE, cada um dos dois mil e setenta CNPJs e razões sociais de operadoras ativas cadastradas na ANS até o ano de 2008. A pesquisa foi realizada em dois campos disponíveis no site TSE. Nas informações por "doador", foi possível obter, a partir da relação do cadastro da ANS, quais foram os planos de saúde doadores, os candidatos beneficiados e o montante doado pela empresa de plano de saúde para cada candidato. Estas informações foram cotejadas e conferidas com as informações disponíveis no site do TSE, no campo "por candidato", no qual foi possível obter a relação de todos os doadores para cada candidato.

Foram, assim, agrupadas informações referentes a empresas de planos de saúde doadoras (razão social, CNPJ e total doado) e candidatos eleitos e não eleitos beneficiados pelas empresas de planos de saúde (nome, partido, cargo eletivo, razão social do(s) doador(es) e total recebido).

\section{Um levantamento exploratório}

Nas eleições de 2006, as empresas de planos de saúde doaram, oficialmente, mais de sete milhões de reais aos candidatos aos cargos de deputados estaduais, deputados federais, senadores e governadores.

Foram identificadas, em 2006, doações contabilizadas de 62 empresas de planos de saúde. Ao se analisar por segmento de atuação dos planos de saúde, fica evidente a predominância da participação das cooperativas médicas, que foram responsáveis por $75,7 \%$ do total das doações, contra $24,3 \%$ das empresas de Medicina de Grupo. Também chama a atenção a completa ausência, nas doações contabilizadas, das seguradoras de saúde entre os doadores (Sul América, Bradesco etc.), talvez porque sejam apenas um ramo de empresas maiores que atuam com seguros em geral ou no mercado financeiro.

No caso dos planos de saúde de autogestão, também não foi computada nenhuma doação nas eleições de 2006, embora algumas empresas que mantêm planos próprios para seus empregados tenham contribuído (na condição de empresa, não de plano de saúde) com campanhas eleitorais. Já os hospitais filantrópicos que comercializam planos de saúde próprios são proibidos, pela legislação eleitoral, de doar recursos para campanhas eleitorais.

As três maiores empresas doadoras são cooperativas médicas/Unimeds (Federação das Unimeds do Estado de São Paulo, Unimed Cooperativa Médica, e Unimed do Estado do Paraná). Juntas, doaram mais de $50 \%$ do total dos recursos declarados pelas empresas do segmento de assistência suplementar. Somente a Federação das Unimeds do Estado de São Paulo doou, aproximadamente, 40\% do total. Em seguida, em quarto e quinto lugares, estão dois planos de Medicina de Grupo: Medial Saúde (incorporada à Amil em 2009) e Golden Cross. A participação das Unimeds contrasta com a inexpressiva contribuição declarada, por exemplo, pela Amil, que já era, em 2006, a maior empresa de Medicina de Grupo e ficou em $51^{\circ}$ lugar no ranking de doações. Em 2006, foram eleitos 28 deputados federais que tiveram, entre seus doadores declarados, empresas de planos de saúde. Dentre os eleitos, apenas seis têm profissões diretamente ligadas à saúde, todos médicos.

Essas doações parecem ter sido relevantes para o apoio financeiro às campanhas de determinados parlamentares eleitos. Dentre os 28 deputados federais inicialmente eleitos com apoio de empresas de planos de saúde privados, mais o suplente conduzido à vaga, 14 integravam a Frente Parlamentar da Saúde. Fundada em março de 1993, a Frente, segundo seu estatuto, visa "trabalhar, solidária e coordenadamente, para transformar em realidade viva e concreta do povo brasileiro os princípios doutrinários e constitucionais que entendem a Saúde como o bem mais precioso da vida, direito social inalienável e responsabilidade maior do Estado".

A Frente contava, em junho de 2007, com a adesão de 248 deputados federais e 27 senadores. Vale destacar sua participação decisiva na aprovação de importantes proposições em defesa do Sistema Único de Saúde, a exemplo da Emenda Constitucional n 29 e outros embates para preservar a arquitetura 
jurídico-legal do sistema de saúde aprovada pela Constituição de 1988. Porém, a defesa de interesses do setor privado, especialmente na área de prestação de serviços, também integra o programa de trabalho desses parlamentares.

Em geral, os discursos de membros da Frente Parlamentar evocam as empresas de planos privados de saúde para argumentar a favor da defesa do equilíbrio do SUS (Garcia, 2004). Nesse sentido, as informações sobre a doação de planos de saúde privados não autorizam uma inferência automática entre a origem da doação e a vocalização, a posteriori, na atuação de membros da Frente Parlamentar em defesa dos interesses exclusivos dessas empresas.

Quanto aos deputados estaduais, dentre os eleitos, 27 receberam doações de empresas de planos de saúde, sendo nove de São Paulo, seis de Santa Catarina, cinco do Paraná e quatro do Rio Grande do Sul. Os Estados de Minas Gerais, Amazonas e Sergipe elegeram apenas um deputado cada, com ajuda dos planos de saúde. Nos demais estados, nenhum deputado estadual eleito declarou doação de empresa de plano de saúde.

Apesar de as Assembléias Legislativas e os Executivos estaduais não serem espaços decisivos da regulamentação dos planos de saúde, matéria de âmbito nacional, a eleição de deputados estaduais (assim como de vereadores, governadores e prefeitos) comprometidos com o setor de assistência suplementar guarda duas principais lógicas: 1) o interesse dos planos de saúde nas políticas fiscais estaduais e municipais, que podem se traduzir em isenções e benefícios para as empresas de planos de saúde, como já ocorre com algumas vantagens locais proporcionadas às cooperativas médicas e medicinas de grupo; 2) a ampliação do leque de articulações políticas que extrapolam os limites dos municípios e estados, mas que passam a contar com o apoio das lideranças políticas locais.

Conforme as doações contabilizadas, três dos governadores eleitos em 2006 foram apoiados por empresas de planos privados de saúde - no caso, a Medial, Federação das Cooperativas Médicas do Rio Grande do Sul e Ascon - Associação de Amparo à Qualidade Médica -, totalizando, aproximadamente, trezentos e trinta mil reais. Cumpre ressaltar, portanto, com base nos registros oficiais do TSE, a preferência das empresas do segmento de assistência suplementar pelo apoio às candidaturas proporcionais. Também foram identificados inúmeros candidatos não eleitos, aos diversos cargos em disputa nas eleições de 2006, que foram beneficiados por doações de planos de saúde privados.

\section{As doações pluripartidárias}

Ao se analisar a distribuição de recursos entre os partidos dos candidatos que foram beneficiados com doações dos planos de saúde, independente de terem ou não sido eleitos, percebe-se que o partido mais beneficiado foi o DEM (antigo PFL), com $24,53 \%$ das doações ( $R$ \$ 1,75 milhão), seguido do PSDB (com 17,98\% ou R $\$ 1,28$ milhão) e o PV (com 16,33\% ou R $\$ 1,16$ milhão). Juntos, os candidatos das três siglas receberam quase $60 \%$ das doações. Os maiores beneficiados compõem a base de partidos de oposição ao governo na Câmara na última legislatura.

Na hipótese de nova proposta do Executivo para regulamentação dos planos de saúde que, supostamente, viesse a contrariar interesses empresariais, a análise da movimentação das bancadas da oposição deveria levar em conta a contribuição dos planos de saúde para campanhas de parlamentares desses partidos.

Os partidos PSB, PPS, PDT e PT receberam, juntos, um quarto das doações dos planos de saúde a candidatos, com cifras que vão de R\$ 301 mil (PT) a R \$ 656 mil (PSB). Chama atenção a dispersão das doações: candidatos de 17 partidos diferentes as receberam sugerindo uma distribuição, do ponto de vista político-partidário, bastante diversificada das doações.

\section{Os planos de saúde no Parlamento}

Os vários projetos de lei sobre planos de saúde em tramitação em 2009 eram de autoria de deputados de vários partidos políticos e tratavam, fundamentalmente, de cinco temas: 1) coberturas (alguns dispõem sobre a ampliação e outros sobre a redução da abrangência dos contratos); 2) critérios para a definição dos honorários médicos; 3) critérios para o credenciamento dos médicos; 4) regras para o 
ingresso de pacientes vinculados ou não a planos ou seguros de saúde em estabelecimentos de saúde públicos e privados; 5) provimento de recursos para conferir suporte financeiro aos estabelecimentos de saúde filantrópicos e privados. Os projetos de lei levam em conta a configuração dos planos de saúde como parte integrante do sistema de saúde brasileiro. Daí, as inclinações dos representantes políticos pela mitigação de determinados problemas e pela renúncia à responsabilidade de contribuir para a defesa de interesses públicos universais. Um mesmo partido, por vezes, o mesmo deputado, absorve demandas particularistas e contraditórias entre si. Assim, a função de representação política fica obscurecida pela preponderância da defesa de interesses de determinados segmentos político-econômicos.

\section{A reforma política no Brasil}

Sem consenso entre partidos e parlamentares, uma das propostas de reforma política prevê o financiamento das campanhas eleitorais exclusivamente com dinheiro público, com a definição de que doações de pessoas físicas e empresas estariam proibidas e sujeitas à punição. Conforme a proposta, nos anos eleitorais, seriam incluídos, na Lei Orçamentária, créditos adicionais para financiar campanhas eleitorais com valores equivalentes ao número de eleitores do País.

A proposta de financiamento público, embora meritória, traz a noção equivocada de que, ao ser eliminada a possibilidade de empresas privadas financiarem legalmente campanhas eleitorais, desapareceria a motivação para que elas procurassem influenciar decisões legislativas e executivas de forma a satisfazer seus interesses. A estipulação legal não eliminaria a motivação material, pois os interesses privados sempre agirão ao lado do Estado na busca da satisfação de seus pleitos. A lógica que governa o financiamento eleitoral não é a lógica das leis, mas a lógica do mercado, da oferta e da procura (Abramo, 2007).

Outra crítica que pesa sobre a chamada reforma política é a de que as propostas até agora viabilizadas têm caráter apenas de reformar o sistema eleitoral, e não preveem a reforma de quem e como se exerce o poder, e dos mecanismos existentes para controlar o poder. Historicamente, a reforma política entra na pauta do Congresso e do Executivo brasileiro em momentos de escândalos, crises políticas ou de fragilidade da hegemonia do grupo que está no poder. A verdadeira reforma política não se reduz à reforma do voto, dos partidos ou da representação, mas sim à reforma das instituições políticas e do Estado, criando uma nova forma de se exercer o poder e com mecanismos de controle público do Estado. Por isso, devia partir da necessidade da ampliação da democracia participativa, dos espaços de participação dos cidadãos (Moroni, 2007).

\section{Corrupção, lobby e loteamento de cargos}

No Brasil, é difícil distinguir as relações entre as redes de influência (networking/ lobbies) e o financiamento das campanhas eleitorais e corrupção. Embora esteja claro que fazer lobby não é necessariamente sinônimo de corrupção, também é evidente a percepção de que a área cinzenta mais perigosa de interpenetração entre o lobby e a corrupção é o financiamento das campanhas eleitorais.

A rigor, o lobby e a corrupção seriam mutuamente excludentes. O lobby é um empreendimento caro, que mobiliza especialistas e tem resultados incertos, enquanto as práticas corruptas recorrem a meios mais diretos e eficazes. Segundo a literatura especializada, há pouco espaço para o lobby em países nos quais a corrupção é generalizada (Oliveira, 2004).

O lobby é uma alternativa ao "neocorporativismo" (Werneck Vianna, 1995), uma forma de articulação de interesses já arraigada na sociedade brasileira. A organização do Estado brasileiro, muito permeável ao particularismo, contribuiu para o desenvolvimento do lobby. A existência de partidos políticos fracos também demonstra um desvirtuamento da função legislativa, que leva a uma certa confusão entre o que é público e o que é privado (privatização do público).

Nos EUA, o lobby é legalizado, uma lei de 1995 determina em quais situações as empresas ou organizações (norte-americanas ou estrangeiras) devem registrar, na Câmara e no Senado, quem fará lobby sobre o Congresso e o governo, tendo como diretriz revelar abertamente os interesses legislativos e os meios financeiros envolvidos. 
No Brasil, a despeito do generalizado reconhecimento das práticas de lobby, não há unanimidade sobre os possíveis benefícios do enquadramento legal. Em 2009, tramitavam, a passos lentos, oito projetos na Câmara Federal que versavam sobre a regulamentação do lobby, incluindo proposta de legalização e registro da atividade dos lobistas, com prestação de contas de suas atividades.

As crises no Congresso Nacional, as muitas Comissões Parlamentares de Inquérito e as denúncias sobre os critérios que favorecem determinados grupos econômicos e políticos na escolha de cargos públicos podem ser atribuídas à utilização e aceitação de mecanismos de pressão invisíveis. Na raiz do debate, situa-se a diferença entre o conceito de lobby (que estaria associado à visibilidade $e$ transparência dos canais de comunicação da sociedade com o Poder Legislativo) e a corrupção (ilegalidade contida nos escândalos decorrentes, por exemplo, de licitações direcionadas e do tráfico de influência).

Além disso, a maioria dos projetos em tramitação no Congresso Nacional tem origem no Executivo, o que induz os lobistas a atuarem nos dois poderes. Uma das práticas que mais favorece a corrupção no setor público é a distribuição de cargos sem base em critérios técnicos, visando garantir "pedaços" da máquina pública a partidos políticos ou grupos constituídos.

Nesse sentido, a produção legislativa voltada a atender interesses dos planos de saúde, a suposta indicação de cargos da ANS, poderia plasmar conflitos de interesse. Adicionalmente, a atuação dos parlamentares, junto a Ministérios e órgãos do governo federal, na defesa da contratação de determinados planos privados para atender ao funcionalismo público, constituiria uma terceira vertente de ações particularistas.

As denúncias de corrupção envolvendo instituições e recursos da área da saúde no Brasil sempre ocuparam papel destacado na mídia. A promessa de medidas enérgicas contra a corrupção tem integrado a plataforma de diversas candidaturas aos cargos majoritários e proporcionais. Contudo, a transposição dos discursos eleitorais para efetivas políticas de controle da corrupção parece requerer mais do que o desenho de medidas burocráticas difusas. Os avanços introduzidos pelo acesso a informações permitem aprimorar o acompanhamento da execução dos orçamentos públicos, mas ainda não são suficientes para desvelar e reverter as complexas interações político-econômicas que ratificam e perenizam dispositivos inadequados de compras e aquisições de produtos, insumos e serviços. A lei que exige a "ficha limpa" para os candidatos, em vigor desde junho de 2010, tornando inelegíveis candidatos condenados por órgão colegiado em crimes como: improbidade administrativa, abuso de autoridade, racismo, tortura, abuso sexual, formação de quadrilha, crimes contra a vida e crimes hediondos, dentre outros - foi um sinal promissor de reversão do atual padrão de intermediação de interesses.

A visibilidade de tramas corruptas tem sido sazonal, concentrada no período eleitoral. A ênfase na busca de vilões e heróis que acompanham esse processo reforça a efêmera perspectiva de soluções simplistas para dar cabo da corrupção e das condutas antiéticas. A notoriedade e a disseminação dos casos de corrupção na saúde e em outras áreas não resultaram na identificação e punição dos responsáveis.

Portanto, é preciso aprofundar o conhecimento sobre a gênese dos processos de corrupção na saúde, bem como elaborar estratégias para seu enfrentamento e prevenção.

\section{Considerações finais}

Ainda que as informações oficiais disponíveis sobre os doadores e os beneficiários do apoio financeiro das empresas de planos e seguros de saúde privados não retratem toda a movimentação de recursos nas campanhas eleitorais, é possível, com base nos dados disponíveis, elencar algumas tendências do financiamento:

1) As empresas de planos de saúde privados contribuíram para o financiamento das campanhas de postulantes ao mandato de cargos proporcionais e majoritários nas eleições de 2006, tanto para as eleições de deputados estaduais, federais quanto para governadores, sugerindo o interesse desse segmento econômico pelo acompanhamento de políticas públicas em todas as esferas de governo. 
2) As empresas de planos de saúde privados apoiam candidatos de diversos partidos políticos. Embora existam alguns indícios, como o maior volume de recursos destinados ao apoio a candidatos de partidos situados mais a centro-direita no espectro ideológico, o mercado da saúde suplementar também financia candidatos de partidos considerados de esquerda.

3) A opção pelo apoio a candidatos localizados na mesma unidade federada da empresa de plano privado de saúde, ou em territórios contíguos, parece orientar uma parte da escolha dos destinatários das doações. Mas existem candidatos que foram apoiados por empresas sediadas e atuantes em várias unidades da federação, o que parece indicar expectativas de um desempenho parlamentar voltado à defesa em bloco ou em "bancada" do interesse setorizado.

4) Há preferência pelos candidatos médicos, mas essas empresas não excluem o apoio a candidatos de outras áreas profissionais, que podem se apresentar diretamente como defensores dos interesses dos planos de saúde, mas que, também, podem estar ligados a plataformas de outras políticas setoriais.

5) Alguns candidatos receberam doações mais vultosas de determinadas empresas de planos de saúde, sendo que, em certos casos, o segmento suplementar foi quase que a fonte de financiamento exclusiva de suas campanhas. Essa especialização das fontes de financiamento pode ser indicativa de "apostas" na atuação particularista do representante político.

6) Alguns candidatos foram apoiados por mais de uma empresa de plano privado de saúde, sendo que, em alguns casos, por uma cooperativa médica e uma empresa de medicina de grupo, o que sugere a possibilidade de uma atuação em defesa de interesses comuns ao segmento suplementar.

As tendências de conformação de uma rede de defesa de interesses privados poderão se acentuar ou, em sentido oposto, tornarem-se menos evidentes quando defrontadas com certas causas de grande amplitude e de interesses públicos difusos. Não há dúvidas de que o lobby exclui severamente muitos interesses sociais. É necessário, portanto, tornar a representação de interesses privados, ainda que legítimos, mais transparente, equitativa, menos fragmentada e mais próxima da defesa dos interesses da sociedade sub-representados. Somam-se a isso: o combate sistemático à corrupção; o aprofundamento do debate sobre o lobby e pressões exercidas por interesses particulares no Congresso Nacional; uma reforma política que viabilize a democracia participativa; o fim do "loteamento" político de cargos e postos estratégicos no Ministério da Saúde e em suas agências reguladoras. Estamos diante de desafios inadiáveis, colocados aos partidos políticos e às entidades da sociedade civil que postulam a defesa do interesse público, do bem comum e da cidadania plena.

\section{Colaboradores}

Mário Scheffer e Lígia Bahia participaram, igualmente, de todas as etapas de elaboração do artigo. 


\section{Referências}

ABRAMO, C.W. Proibição fantasiosa. Folha de S. Paulo, São Paulo, 19 jun. 2007. Tendências e Debates, p.A3.

ARAGÃO, M. Grupos de pressão no Congresso Nacional: como a sociedade pode defender licitamente seus direitos no poder Legislativo. São Paulo: Maltese, 1994.

CARDOSO, F.H. Autoritarismo e democratização. Rio de Janeiro: Paz e Terra, 1975.

GARCIA, M. A Comissão Parlamentar de Inquérito dos planos de saúde. 2004. Dissertação (Mestrado) - Núcleo de Estudos de Saúde Coletiva, Universidade Federal do Rio de Janeiro, Rio de Janeiro. 2004.

MORONI, J.A. Reforma política ampla, democrática e participativa. Disponível em: <http:// www.inesc.org.br/equipe/jairb/textos-para-reflexao-e-debate/reforma-politica-ampla-democratica-eparticipativa/view>. Acesso em: 11 jun. 2007.

OLIVEIRA, A.C.J. Lobby e representação de interesses: lobistas e seu impacto sobre a representação de interesses no Brasil. 2004. Tese (Doutorado) - Universidade Estadual de Campinas, Campinas. 2004.

PEREIRA, C. A política pública como caixa de pandora: organização de interesses, processo decisório e efeitos perversos na Reforma Sanitária Brasileira - 1985-1989. Dados, v.39, n.3, p.423-78, 1996.

PILATT, A. A perspectiva institucionalista e a análise da dinâmica das decisões legislativas. Direito, Estado Soc., v.9, n.29, p.28-48, 2006.

RODRIGUES, L.M. Partidos, ideologia e composição social: um estudo das bancadas partidárias na Câmara de Deputados. São Paulo: Edusp, 2002.

SANTOS, F.G.M. Novas e velhas verdades sobre a organização do poder Legislativo e a democracia. Dados, v.4, n.4, p.863-73, 1998.

WERNECK VIANNA, M.L.T. Articulação de interesses, estratégias de bem-estar e políticas públicas: a americanização (perversa) da seguridade social no Brasil. 1995. Tese (Doutorado) - Instituto Universitário de Pesquisas do Rio de Janeiro, Rio de Janeiro. 1995. 
A legislação brasileira normatiza a doação de recursos financeiros provenientes de fontes privadas para as campanhas de candidatos majoritários e proporcionais. Com base em aportes da literatura sobre a estrutura partidária e relações entre o Legislativo e Executivo, o presente estudo analisa, a partir das categorias de representação política e de interesses, as informações sobre empresas de planos de saúde doadoras e as candidaturas destinatárias. As empresas de planos de saúde doadoras foram devidamente identificadas, assim como os recursos doados para candidatos. $\mathrm{O}$ cotejamento desses dados fornece um mapeamento de interesses das empresas de planos de saúde projetados no Poder Legislativo, mas não autoriza o estabelecimento de relações causais entre os doadores e a atuação dos parlamentares. $\mathrm{O}$ comparecimento das empresas de planos de saúde na disputa eleitoral e a inclinação das doações para partidos situados mais à direita no gradiente político partidário são os principais resultados do trabalho.

Palavras-chave: Planos e seguros de saúde privados. Lobby. Campanhas eleitorais. Sistemas de financiamento. Financiamento em saúde.

Political representation and private interests in health: a case study on the financing of voting campaigns by private health plans in Brazil

The Brazilian legislation regulates the financial donations from private sources to both majoritarian and proportional election candidates. Based on approaches found in the literature on the party-system structure and on the relationships between the Legislative and Executive, this study uses the categories political representation and interests to analyze the information on donating health insurance companies and the receiving candidacies. The donating health plan companies were duly identified, as well as the resources donated to candidates. Comparing these data allows an assessment of the health plan companies' interests projected in the Legislative Power, but does not authorize the establishment of causal relationships between donors and the representatives' performance. The presence in the electoral dispute of health plan companies from every region in the country and the tendency of donations to go to parties on the right of the political spectrum are the major findings of this paper.

Keywords: Private health plans and insurance. Lobby. Electoral campaigns. Financing systems. Health financing.

Representación política y los interesses privados en materia de salud: el caso de la financiación de las campañas electorales por compañías de planos de salud privados en Brasil

La ley brasileña regula la donación de recursos financieros provenientes de fuentes privadas a los candidatos a las elecciones. Sobre la base de la literatura sobre la estructura partidaria y las relaciones entre el poder legislativo y el poder ejecutivo, este estudio examina, desde las categorías de la representación política y de intereses, la información sobre empresas de planos de salud donantes y las candidaturas destinatarias. Las empresas de plano de salud donantes fueren debidamente identificadas, así como los recursos donados a los candidatos. La comparación entre estos datos proporciona una asignación de los intereses de las empresas de planes de salud involucrados en el poder legislativo, pero no autoriza el establecimiento de relaciones causales entre donadores y la actuación de los parlamentarios. A presencia de las compañías de seguros de salud durante la campaña electoral y la inclinación de las donaciones a los partidos situados más a la derecha en el gradiente políticopartidario son los principales resultados del trabajo.

Palabras clave: Compañías y seguros de salud privados. Lobby. Campañas electorales. Sistemas de financiación. Financiación de la salud. 